\title{
Tako-Tsubo syndrome. Approach to the subject and Report of 2
}

\section{cases}

\author{
Lázaro A Mata Cuevas ${ }^{1}$, Jesús J Roque Corzo ${ }^{2}$, Modesto González Cortiñas ${ }^{3}$, Celibel García Meneses ${ }^{4}$, Lídice Corzo González ${ }^{5}$, Claribel Plain \\ Pazos $^{6}$
}

${ }^{1}$ I Degree Specialist in Cardiology and I Degree in MGI, Assistant Professor, Provincial General University Hospital "Mártires del 9 Abril", Sagua la Grande, Villa Clara, Cuba.

${ }^{2}$ I Degree Specialist in Internal Medicin andII Degree in Cardiology, Assistant Professor, Provincial General University Hospital "Mártires del 9 de Abril", Sagua la Grande, Villa Clara, Cuba.

${ }^{3}$ II Degree Specialist in Internal Medicin, Assistant Professor, Provincial General University Hospital “Mártires del 9 de Abril”, Sagua la Grande, Villa Clara, Cuba.

${ }^{4}$ I Degree Specialist in Cardiology, Assistant Professor, Provincial General University Hospital "Mártires del 9 Abril", Sagua la Grande, Villa Clara, Cuba.

${ }^{5}$ Degree in psychology Provincial General University Hospital "Mártires del 9 Abril", Sagua la Grande, Villa Clara, Cuba.

${ }^{6}$ Specialist of I and II Degree in Comprehensive General Medicine, Assistant Professor, Faculty of Medical Sciences of Sagua la Grande, Cuba.

*Corresponding Author: Claribel Plain Pazos, Specialist of II Degree in Comprehensive General Medicine, Assistant Professor, Faculty of Medical Sciences of Sagua la Grande, Villa Clara, Cuba.

\section{Received Date: 23 June 2021 | Accepted Date: 03 August 2021 | Published Date: 12 Augusł 2021}

Citation: J J R Corzo, Modesto G Cortiñas, Celibel G Meneses, Lídice C González, Claribel P Pazos. (2021) Tako-Tsubo syndrome. Approach to the subject and Report of 2 cases. Biomedical Research and Clinical Reviews. 4(4); DOI: 10.31579/2692-9406/074

Copyright: (c) 2021 Claribel Plain Pazos, This is an open-access article distributed under the terms of the Creative Commons Attribution License, which permits unrestricted use, distribution, and reproduction in any medium, provided the original author and source are credited.

\begin{abstract}
Takotsubo syndrome, or stress cardiomyopathy, is a relatively rare transient and reversible cardiomyopathy, although its diagnosis has increased in recent years, it presents as an acute coronary syndrome (ACS) or acute heart failure, its incidence is unknown exactly in Latin America and in Cuba. We present 2 cases seen in our hospital, both 63 and 55-year-old women with typical precordial pressure pain, the first triggering psychological stress and the second physical, with electrocardiographic changes consistent with anterior infarction and cardiogenic shock, which were found in the coronary angiographic study observed normal coronary arteries and ventriculography determined apical ballooning of the left ventricle characteristic of the syndrome, with subsequent recovery and favorable clinical evolution at 6 months.

Key Words: takotsubo syndrome; acute coronary syndrome; transient anteroapical dyskinesia; normal coronary arteries
\end{abstract}

\section{Introduction}

Cardiomyopathy or Tako-tsubo syndrome, an entity described by Sato et al. in 1990 [1] a little over three decades ago, (also known as transient apical left ventricular (LV) dyskinesia, stress-induced cardiomyopathy [2], broken heart syndrome and apical bulging) [3], named for the characteristic shape that it adopts in the left ventricle, very similar to the vessel used by Japanese fishermen to catch octopus [1]. It is characterized by transient dysfunction of the left ventricle (LV), which presents an abnormal movement pattern that cannot be explained by diseases such as coronary ischemia, aortic valve injury, or myocarditis [4]. In this pathology, the apex appears rounded and hypocontractile during systole (a compromise that also affects the distal half of the anterior, inferior and lateral walls), associated with a narrow base, due to compensatory hyperkinesis of the basal walls [5-7]. In its characteristic clinical manifestation, it presents as an acute coronary syndrome (ACS) $[2,3]$ that also presents electrocardiographic alterations and elevated cardiac biomarkers; predominates in middle-aged women (between 50 and 70 years) $[2,8-9]$, and is generally precipitated by severe physical or psychological stress $[2-4,7]$ with a low ejection fraction that is fully recovered in about a month, so his prognosis is excellent [2.4].

There are numerous diagnostic criteria developed since 2003, the most widely used being those of the Mayo Clinic [6], and ventriculography 
continues to be the gold standard for diagnosis. In 2018, the consensus group that studied this syndrome developed the Inter TAK Diagnostic Criteria [8], based on current knowledge, which are:

- Transient LV dysfunction (hypokinesia, akinesia, dyskinesia) expressed as apical, mid-ventricular, basal or focal ballooning. There may be RV commitment. The wall motion abnormality usually exceeds the epicardial vascular distribution of a coronary artery. Medioventricular, apical, basal or to an isolated segment, with possible involvement of the right ventricle.

- Emotional, physical, or combined triggers can precede the syndrome, but are not required. Neurological disorders (SAH, stroke, seizures) and pheochromocytoma can trigger the syndrome.

- New ECG abnormalities (ST segment elevation or depression, T wave inversion, QT interval prolongation).

- There may be no changes. Moderate elevation of cardiac biomarkers (troponins, creatine kinase) and significant increase in brain natriuretic peptide.

- The presence of significant CAD does not exclude the diagnosis of Takotsubo syndrome.

- Absence of myocarditis.

- It predominantly affects postmenopausal women.

Tako-Tsubo syndrome is diagnosed in approximately 1-3\% of patients with ACS symptoms; however, the prevalence is likely underestimated. About $90 \%$ of patients with the syndrome are female, usually postmenopausal, although the number of younger and male patients diagnosed has been increasing due to a greater understanding of the syndrome.

Psychological triggers or triggers include multiple traumatic emotions, both positive (surprise parties) and negative (grief, fear, panic, anger, anxiety, financial problems, natural disasters). Physical triggers can be related to physical activity, medical conditions or procedures.

Various theories are invoked in pathophysiology [11].

Theory of alteration in the autonomic nervous system:

1. In one study it was found that years after the event of Takotsubo syndrome patients showed exaggerated sympathetic responses to emotional and hemodynamic stress in combination with suppressed parasympathetic (vagal) modulation of the heart. It is reported that the distribution of adrenergic receptors in the myocardium of women who had recovered from this syndrome, compared to healthy women, had an autonomic phenotype that could predispose towards prolonged sympathetic activation. Decreased parasympathetic modulation of the heart, as well as alterations in sympathetic moderation are the main probable causes of this syndrome $[13,14]$. The reduction in parasympathetic modulation of the heart is important, because it has been associated with sudden death, increased mortality in heart failure, and acute myocardial infarction $[11,14]$.

2. Genetics

The stress trigger involved in the pathophysiology of the syndrome has a strong environmental component. However, it is conceivable that some people have a genetic predisposition to suffer from stress-induced Tako-tsubo syndrome. The existence or absence of functional polymorphisms in genes, such as alpha 1, beta 1 and beta 2 adrenergic receptors, GRK5, and the involvement of estrogens have been reported; however, larger studies are needed to corroborate this [13].

3. Theory of excess catecholamines
The potential role of excess catecholamines in the pathogenesis of Takotsubo syndrome has long been the pathophysiological explanation of choice, which is why beta-blockers have been considered as a therapeutic strategy [4]. The pathophysiology of the syndrome is complex, reflecting the physiological, local, and systemic responses to acute stress and cardiovascular responses to sudden increases in catecholamines [15]. The trigger is often sudden stress, sympathetic activation signals are present in the manifestation and can lead to extreme sympathetic activation. There are two initial elements of physiology to consider: The first is that of the brain's cognitive centers, the hypothalamic-pituitary-adrenal axis, and the amount of adrenaline-norepinephrine that are released in response to a given stress. The second is the response of the system cardiovascular (including myocardium, coronary arteries, and peripheral musculature), the sympathetic nervous system to sympathetic activation, and the sudden surge of circulating catecholamines [9]. Serum catecholamine concentrations at presentation are significantly higher than resting concentrations in the same patient, comparable with acute heart failure due to acute myocardial infarction, suggesting the possibility of excess and epinephrine elevation.

Clinically in the acute phase, the clinical manifestation, electrocardiographic findings, and biomarker profiles are often similar to those of an acute coronary syndrome. The predominant symptom in the emergency room was chest pain (76\%), followed by dyspnea (47\%) and syncope (8\%) [11]. Other symptoms include acute pulmonary edema, as well as cardiac arrest, cardiogenic shock, and severe ventricular arrhythmias. Non-specific symptoms have reported weakness, cough, and fever [14].

In general, the symptoms are transitory and resolve in the course of days, it is much more frequent in women; however, males have three times the risk of death from cardiac and cerebrovascular events. The most frequent complications during admission include: acute heart failure (12\%-45\%), LVOT obstruction (10\%-25\%), mitral regurgitation $(14 \%-25 \%)$ and cardiogenic shock $(6 \%-20 \%)$. Less frequently, atrial fibrillation (5\% $15 \%), \mathrm{LV}$ thrombus $(2 \%-8 \%)$, cardiorespiratory arrest $(4 \%-6 \%)$, complete atrioventricular block (5\%), tachyarrhythmias and bradyarrhythmias $(2 \%-6 \%)$ are observed. $5 \%)$, and ventricular septal defect $(<1 \%)$ [19].

Recurrence of this syndrome is rare; one study reports that the recurrence rate was greater than $3 \%$ per year in the first four years and the recurrence rate greater than 4 years was $11 \%$ after the initial manifestation [13].

\section{Electrocardiographic findings}

The initial ECG is abnormal in most patients. In the InterTAK registry [8] the frequency of alterations was as follows: $44 \%$ ST segment elevation; $8 \%$ ST segment depression; $41 \% \mathrm{~T}$ wave inversion, and complete left bundle branch block in 5\%. The location of the ST segment elevation and inversion of the $\mathrm{T}$ wave corresponds to the compromised anatomical region, usually the middle and apical $\mathrm{LV}$, being these alterations more noticeable in DII and AVR and in precordial, from V2 to V5 [20]. The ECG shows a temporal evolution with resolution of the ST segment elevation, progressive inversion of the T wave and prolongation of the QT interval for several days, with subsequent normalization in the following weeks [19]. The electro cardiographic evolution shows the progressive normalization of the segment. In the first hours and in the subacute stage, $84 \%$ of patients have ST wave inversion (sometimes giant T waves) with prolongation of the QTc interval (corrected QT interval) and dispersion of the QT interval. From the second day, they can last several weeks and are explained by the great variability between myocardial repolarization 
of the dyskinetic apical zone and the hypercinetic basal zone. Unethical. Only $10 \%$ of patients persist with pathologic Q waves [20].

\section{Biochemical markers}

Peak troponin values are usually lower than in ACS. The presence of high levels at admission predicts a poor prognosis. A substantial increase in brain natriuretic peptide and its prohormone is frequently observed, linked to the degree of sympathetic activation, peak C-reactive protein concentrations, and LV systolic dysfunction.

Ventricular function can be evaluated by transthoracic echocardiography in which patients have a left ventricular ejection fraction (LVEF) of 20 to $49 \%$, and you can see the alterations in contractility with the characteristic configuration.

The diagnosis of this disease is usually confirmed after verifying the absence of atherothrombotic disease in the arteries, about $80 \%$ of patients do not suffer from atherosclerotic obstructions and the rest usually have a mild luminal stenosis of less than $50 \%$. Ventricular function can be assessed by ventriculography and generally improves over a period of days to weeks, achieving an ejection fraction between 60 and $76 \%$. Ventriculography and echocardiography allow us to observe the characteristic morphology of the syndrome in its typical and atypical form $[11,20]$.

The spectrum of STT is broad, ranging from low to very high risk. Inhospital mortality and long-term prognosis of STT are similar to ACS. Recovery from regional left ventricular systolic dysfunction is usually seen after 4-8 weeks. The risk of recurrence is approximately $5 \%$.

\section{Case presentation}

\section{Case 1}

63-year-old MVF patient, female, who is received at our center for presenting intense pain in the precordial region after receiving the news of the death of her sister, arrives sweaty, anxious, with a sensation of imminent death, verifying high blood pressure figures initially (170/90), which then fell sharply (80/30), later evolving with sustained hypotension, thermal gradient above the knee, tachycardia, crackles in both lung bases. An electrocardiogram was performed (Fig. 1) showing ST elevation and negative T from V2 to V6 and PR elevation in DII, DIII, and aVF. Biochemical markers are performed showing elevation of CKMB 13.45ng, and higher Troponin 40ng. It is defined as cardiogenic shock, for this reason it is coordinated with the hemodynamic service in the cardiocentre for coronary angiography with an initial diagnosis of STelevation acute coronary syndrome (STEACS) and a diagnosis of anterior myocardial infarction in carcinogenic shock. Coronary angiography shows normal coronary arteries. Ventriculography (Fig. 2) shows akinesis of apical segments with an image of bulging, characteristic of this syndrome. Given the evidence of the decision to suspend vasoactive drugs, treatment for heart failure was maintained, observing regression of the clinical picture with and normalization of the electrocardiogram. The patient has had a favorable evolution in the following 6 months.

\section{Case 2}

53-year-old female NMR patient, obese, hypertensive, diabetic, with an ulcer in the lower left limb, which after healing it begins with chest pain, fatigue and sweating, for which she is brought to our center. During the physical examination she was found to be sweaty, with a blood pressure of $60 / 0$, a thermal gradient, bibasal crackles, requiring hemodynamic support with vasoactive drugs. Complements are performed where $\mathrm{Ck} \mathrm{Mb}$ $32.4 \mathrm{ng}$ appears slightly elevated and troponin greater than $40 \mathrm{ng}$. The electrocardiogram shows ST elevation from V4 to V6. Coronary angiography was requested from the hemodynamics service of the cardiocenter with an initial diagnosis of STEACS and a diagnosis of anterior myocardial infarction in carcinogenic shock. Coronary angiography is performed, observing normal main coronary arteries. Ventriculography showing apical segment akinesia, with a characteristic bulging image (Fig. 3). Given these evidences, a diagnosis of Tako-Tsubo Syndrome is made, vasopressor drugs are withdrawn, maintaining treatment for heart failure, evolving favorably with ST regression and normal posterior echocardiography. The patient has had a favorable evolution in the following 6 months and a medical and psychological cardiovascular rehabilitation program is included.

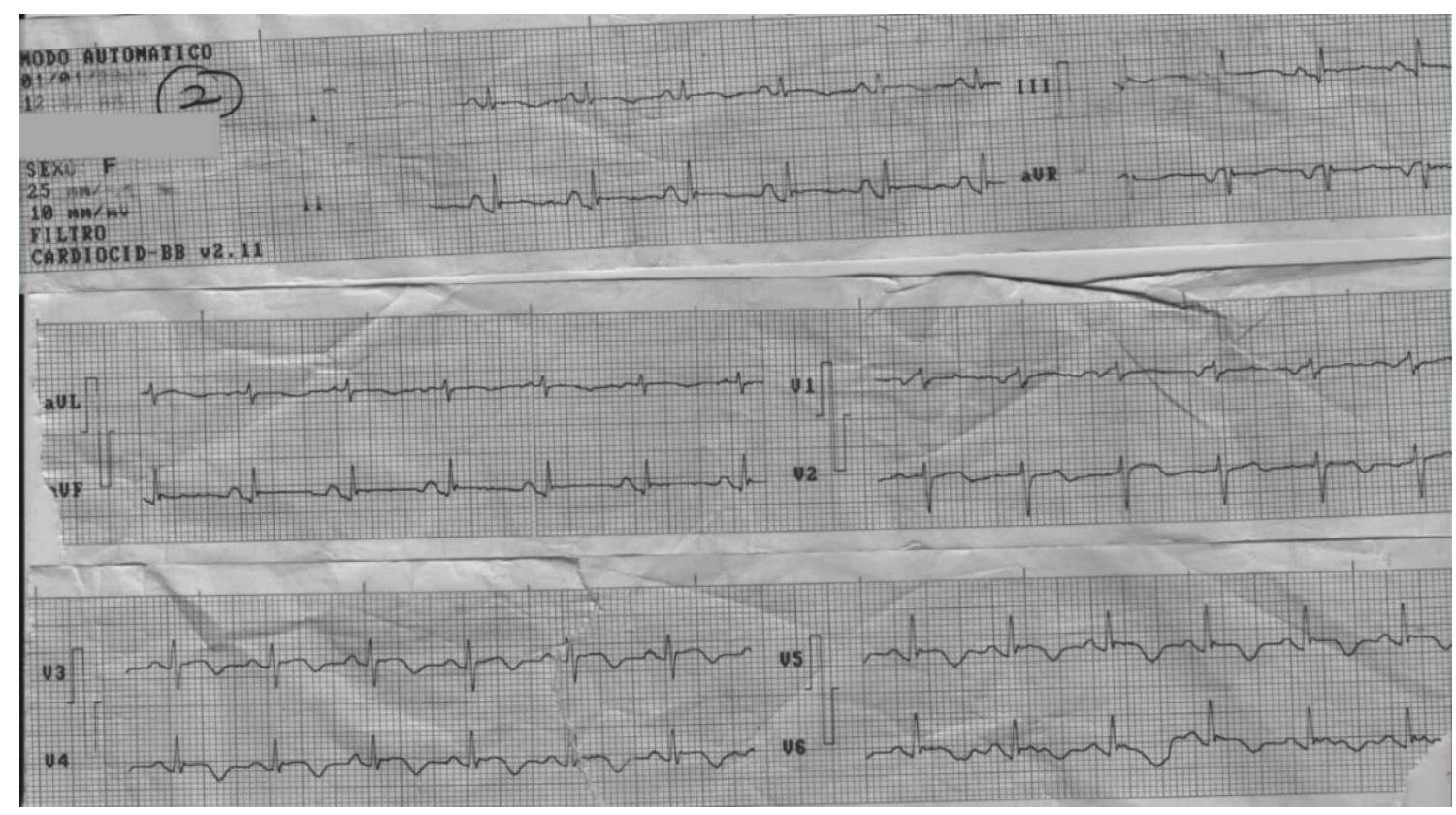

Figure 1: Initial electrocardiogram of case 1 


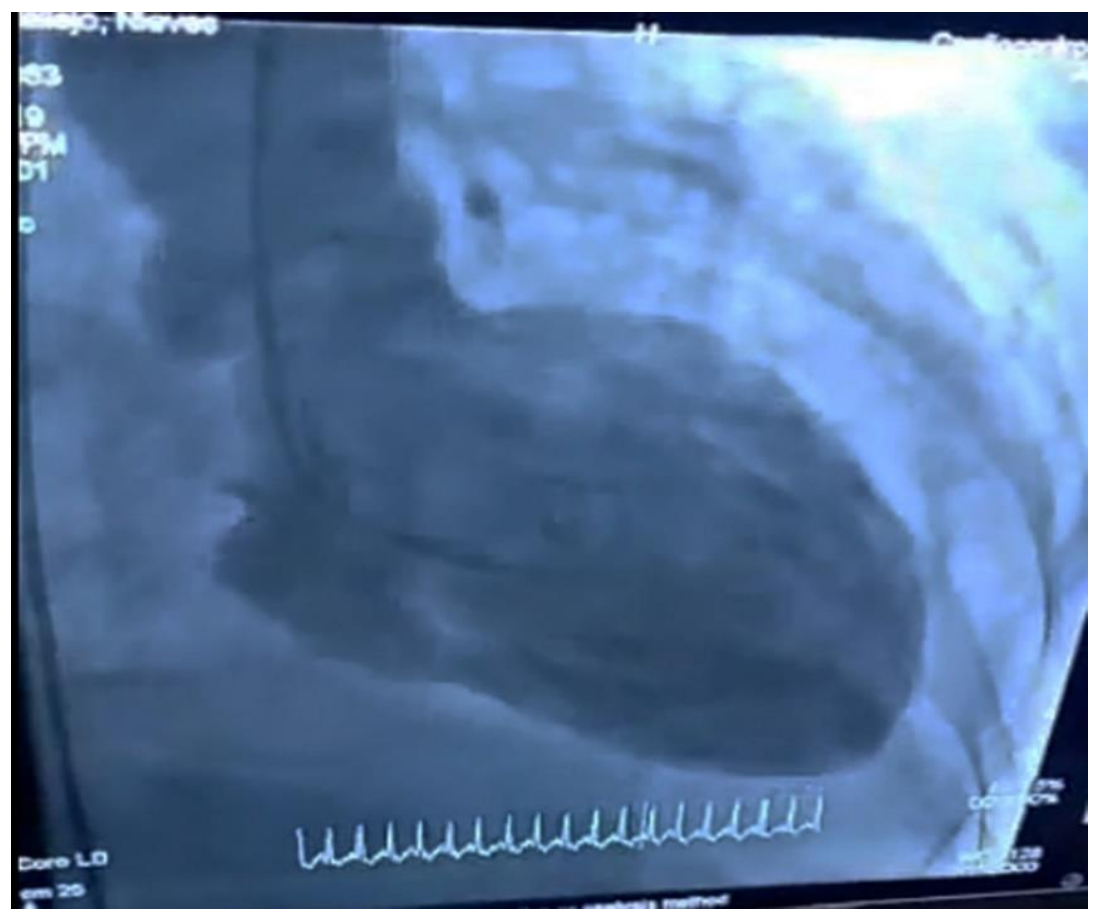

Figure 2: Ventriculography of case No. 1

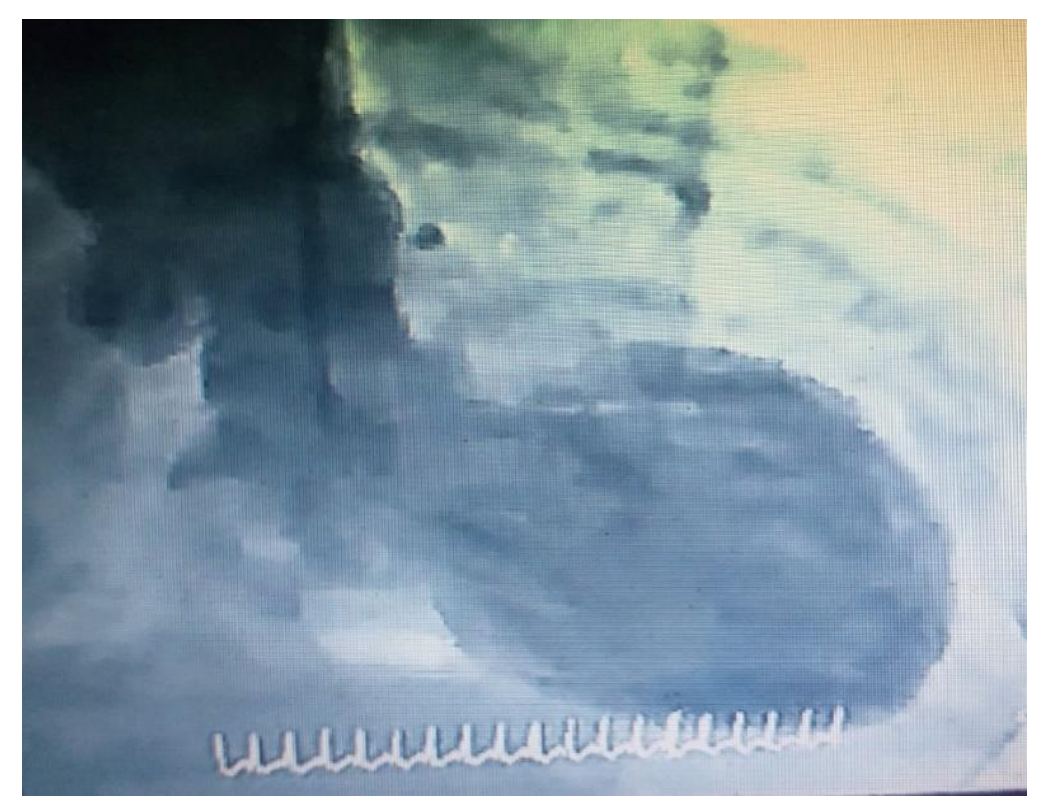

Figure 3: Ventriculography of case No 2

\section{Discussion}

Our two cases are postmenopausal women, the age at which this syndrome most frequently occurs, corresponding to the revised bibliography $[2,4,11,13]$. Both had situations of emotional stress as a trigger, the first related to a situation of mourning due to the death of the sister, and the second related to the healing of an ulcer in the lower limb. These triggering mechanisms are collected in the different studies reviewed, and are included among the diagnostic criteria of the InterTAK consensus. [9] Precordial pain is the most frequent symptom with which these patients attend, in $83.4 \%$ as the presentation, followed by dyspnea $44 \%$ [20]. as it happened in our patients.
Our two patients presented with obvious signs of cardiogenic shock, and although this is referred to as rare in the literature, several case reports indicate it as a form of presentation [13-14, 19]. Representing up to $20 \%$ of the cases, complications [19]. The electrocardiographic alterations observed by us, from the topographic point of view, were of interest in the anterior face, this being the most frequent location reported [11], they were reversible in time. Ventriculography demonstrated the alteration of motility in the apical and septal region of the LV, characteristics that led to the diagnosis, constituting this technique as the golden rule for the diagnosis of the syndrome. 


\section{Conclusion}

Takotsubo syndrome is a condition that, due to its clinical manifestations similar to acute coronary syndrome, may surprise us. Its incidence continues to be low, although it is increasing in relation to the greater knowledge of the syndrome. Our two patients presented with typical oppressive chest pain, electrocardiographic changes concordant with anterior myocardial infarction, and signs of cardiogenic shock, evolving towards full recovery from dyskinesia of the affected segments and having a satisfactory evolution in the subsequent 6 months.

\section{References}

1. Sato H, Tateishi H, Uchida T. (1990). Takotsubo type cardiomyopathy due to multivessel spasm. In: Kodama K, Haze $\mathrm{K}$, Hon M, eds. Clinical aspect of myocardial injury: from ischemia to heart failure. Tokyo: Kagaku hyouronsha. 56-64.

2. Rojas-Jiménez S, Lopera-Valle JS. Cardiomiopatía de Takotsubo, el gran imitador del infarto agudo de miocardio. Rev. CES Med 26(1): 107-120.

3. Sharkey SW, Lesser JR, Zenovich AG, Maron MS, Lindberg J, Longe TF, et al. (2005). Acute and reversible cardiomyopathy provoked by stress in women from the United States. Circulation. 111: 472-479.

4. Sato M, Fujita S, Saito A, Ikeda Y, Kitazawa H, Takahashi M, et al. (2006). Increased incidence of transient left ventricular apical ballooning (so-called "Takotsubo" cardiomyopathy) after the mid-Niigata Prefecture earthquake. Circ J. 70: 947953.

5. Bybee KA. (2008). Prasad A. Stress-related cardiomyopathy syndromes. Circulation. 118(4); 397-409.

6. Prasad A, Lerman A, Rihal CS. (2008). Apical ballooning syndrome (Tako-Tsubo or stress cardiomyopathy): a mimic of acute myocardial infarction. Am Heart J. 155(3):408-417.

7. Arias A, Lucas O, Espinosa E, Iezzi E, et. al. (2018). Características clínicas y evolutivas del síndrome de Takotsubo en un hospital universitario Rev Argent Cardiol. 86:90-95.

8. Bybee KA, Kara T, Prasad A, Lerman A, BarsnessGW, Wright RS, Rihal CS. (2004). Systematic review: transient left ventricular apical ballooning: a syndrome that mimics STsegment elevation myocardial infarction. Ann Intern Med. 141 :858
9. International Expert Consensus Document on Takotsubo Syndrome (Part I): Clinical Characteristics, Diagnostic Criteria, and Pathophysiology. Eur Heart.39(22): 2032-2046.

10. Madias JE. (2014). Why the current diagnostic criteria of takotsubo syndrome are outmoded: a proposal for new criteria. Int J Cardiol. 174:468-470.

11. Morales-Hernández AE, Valencia-López R, HernándezSalcedo DR, Domínguez-Estrada JM. (2016). Sindrome TakoTsubo.Caso Clínico Med Int Méx. 32(4):475-491.

12. Madias JE. (2015). Plausible speculations on the pathophysiology of Takotsubo syndrome. Int J Cardiol. 188:1921.

13. Mora-Aguirre D, Torres-Mejía D, López-Atehortua DF y col. (2011). Enfermedad del corazón roto o síndrome de TakoTsubo. Med UIS. 24:135-140.

14. Cetina-Cámara MA, Collí-Gómez D, Hernández-Gómez F. (2012). Síndrome de TakoTsubo, reporte de dos casos y revisión de la literatura. MedCrit Ter Int. 16; 51-55.

15. Auzel O, Mustafic H, Pillière R, El Mahmoud R, et al. (2016). Incidence, characteristics, risk factors, and outcomes of Takotsubo cardiomyopathy with and without ventricular arrhythmia. Am J Cardiol. 117:1242-1247.

16. Norcliffe-Kaufmann L, Kaufmann H, Martinez J, Katz SD, et al. (2016). Autonomic findings in Takotsubo cardiomyopathy. Am J Cardiol. 117:206-213.

17. Lyon AR, Bossone E, Schneider B, Sechtem U, et al. (2016). Current state of knowledge on Takotsubo syndrome : a position statement from the task force on Takotsubo syndrome of the Heart Failure Association of the European Society of Cardiology. Eur J Heart Fail. 18;8-27.

18. Szardien S, Möllmann H, Willmer M, Akashi YJ, et al. (2013). Mechanisms of stress (Takotsubo) cardiomyopathy. Heart Fail Clin. 9:197-205

19. Sobue Y, Watanabe E, Ichikawa T, Koshikawa M, Yamamoto M, Harada M, Ozaki Y. (2017). Physically triggered Takotsubo cardiomyopathy has a higher inhospital mortality rate. Int $\mathrm{J}$ Cardiol. 235:87-96.

20. Pacheco-Boutiller A, Maza G, Vargas R, Santiago-Hernandez, J, Almeida E, borrallo G. (2010). Sindrome de Tako-Tsubo. Informe de un caso y revisión de la bibliografía. 78; 157-161.
This work is licensed under Creative Commons Attribution 4.0 License

To Submit Your Article Click Here: Submit Manuscript

DOI: $10.31579 / 2692-9406 / 074$
Ready to submit your research? Choose Auctores and benefit from:

$>$ fast, convenient online submission

$>$ rigorous peer review by experienced research in your field

$>$ rapid publication on acceptance

$>$ authors retain copyrights

$>$ unique DOI for all articles

$>$ immediate, unrestricted online access

At Auctores, research is always in progress.

Learn more www.auctoresonline.org/journals/biomedical-research-andclinical-reviews- 